\title{
Analysis of Restraining Factors of the Development of Green Logistics in China
}

\author{
Xiaoran Wang \\ JiLin Railway Technology College, China \\ 38163805@163.com
}

Keywords: Green logistics, Sustainable Development, Restraining Factors

\begin{abstract}
Green logistics bases on the maintenance of the ecological environment and sustainable development. As a new mode of logistics, green logistics represents the direction and trend of logistics development in accordance with the requirements of sustainable development, human survival and development interests in the future,. China's implementation of green logistics has the urgency and necessity. This paper aims to discuss the development of green logistics in the face of problems from the aspects of the policy, ideas, technology, infrastructure level, evaluation and supervision. The comprehensive knowledge and understanding about these problems, is a effective way to find available solutions.
\end{abstract}

\section{Introduction}

Logistics system is the basic system of ensuring the operation of society and economics normally and effectively. However, traditional logistics activity bring some negative effects easily such as noise pollution of transport links, air and waste pollution, the waste of energy, earth and human resource of packing, stevedoring and storing. Thus, international logistics industry began to focus on efficient use of resources, environmental protection and the development of logistics since 1990s, also realize the importance of developing green logistics. Although we make series of rules and regulations accordingly, in the practice we still are faced with many negative factors restrict the benign development of green logistics.

\section{The Conception of Green Logistics}

The formation of green logistics theory bases on theory of sustainable development, theory of ecological economy, theory of ecological ethics and theory of circular economy[1]. It is a modern logistics decision pattern mixed with the concept of environmental protection, which links with manufacturing for environment and green consumption. And it is the long-term benefit strategy of 
reducing energy and resources consumption, decreasing pollution and improving competitive advantage.

Promoting green logistics aim to realize sustainable development of environment, society and economics, which run through the whole produce life cycle. Green logistics play a positive role from obtaining raw materials to using product, even out-of -service.

The behavior subjects of green logistics consist of government, the public and all the members of supply chain. Government plays as decision maker, the members of supply chain are the executor, and the public is the victim of environmental pollution, also is one of the main makers responsible for environmental pollution.

\section{Negative Factors Restrict the Benign Development of Green Logistics}

(1) The customers and logistics enterprises are lack of further understanding about green environmental protect. Package is the end of production process, also is the start of logistics transportation. It has two basic functions, marketing and logistics. For marketing, the effect is providing productions' information to customers through the shape and color of Package, attracting the customers to buy. Meanwhile, the package helps to avoid deterioration, to be rotted and be broken, furthermore increase goods' quality. For logistics, the effect is protecting and identifying productions and their materials. Generally, using bigger and stronger containers to cover productions' package in order to avoid to be knocked, easy to pile up during transporting and storing, and helps to count the quantity and maintain the security in the duration of logistics operation, related to the service level of the enterprise.

However, one side, in the people's consumption concept, products' package is one of the most important decision factors affect customer behavior, especially for Chinese. We always prefer to buy goods have magnificent packaging. Based on the concept, more and more manufacturers follow to use a lot of elegant and luxurious package. But that kind of packages need complex processes, more raw materials to produce, a lot of lumber is needed to produce beautiful and throwaway paper and wood packing, which will result in the decline of forest planting area. On the other side, for logistics enterprises, a large amount of plastic foam and gummed tape is be used in order to save time and cost. Once be abandoned, that materials cannot be degraded. The only way to dispose of the waste is burying and burning, that will lead to the secondary pollution of the earth and air for a long time.

(2) The key of developing green logistics not only depends on the foundation of green logistics ideas, but also the application of green technology. But compared with international advanced level, logistics technology and green demand of our country still has big gaps in the current, and faces all 
kinds of difficulties[2]. The degree of mechanization of logistics has been below the average level of international demand of green logistics. In addition, green logistics conception has not merged into the automatic, networked links of logistics. For the enterprises, there is one issue deserving attention that the operation and control demands are higher than traditional logistics pattern at the technical level. Then green logistics put a special emphasis on integration among design, material, technique, packing and procedure of the green ideas in the product life cycle. That enlarged the difficulties of supply chain management, for example, choosing the materials, in this context it shall consider price, also take fully into account the consideration of green level. In the next, green logistics pattern focuses on knowledge innovation of supply chain members, needs higher technical demand of the management.

(3) Although there are many logistics enterprises at present, with strong competitiveness of the scale, intensive, professional logistics enterprises are not much. Large scale logistics enterprises and small or medium sized enterprises coexist and compete with each other. That causes the whole logistics industry socialization degree is not high, the degree of green logistics development is uneven.

(4) The forms of green logistics policy are guideline and planning, and the goals of the green logistics development policies just rule relatively macro and abstract goals, as general direction and guidance. Although the policies require local government to make further and executable decisions according to the spirit of the policy in the process of implementation, local government just directly execute the policy forwarding, ignore the reality under local conditions. Moreover, our country's green logistics policies lack clear and quantifiable objectives, and the implement department also rarely make phased quantitative criteria and total target, making the implementation of policy is difficult to promote effectively. And owing to the lack of effective supervision and evaluation mechanism, making the policy difficult to evaluate, the implementation in the practice is not reasonable.

(5) The construction level of logistics infrastructure is lagging behind the average level of green degree. The development of logistics industry cannot be separated from a series of infrastructure construction, such as roads, information, terminals, logistics and distribution sites. Although logistics infrastructure of our country has been improved greatly in the current, still has a large gap compared with the developed countries in a considerable extent. That affects the improvement of the efficiency of China's logistics, is not conducive to the healthy and rapid development of green logistics. In the first place, logistics hardware facilities, the modernization level of the logistics of our country are not high generally, the construction of logistics infrastructure are lack of investment, such as the overall size of the transportation infrastructure. Secondly, logistics software, the vast 
majority of logistics enterprises in our country do not have their own logistics information network, can not be optimized scheduling and efficient allocation of logistics resources, the application of new logistics technology is not enough. Thirdly, there are some problems logistics enterprise of our country exists generally in the present, for example, the enterprise scale is small, the logistics system efficiency is low, the overall level is not high. the small-sized enterprise, means the infrastructure is poor, extensive operation, and the efficiency of system and overall level is not high, restricting the development of China's green logistics industry.

(6) With the rapid development of China's logistics industry, the demand of logistics personnel also increased dramatically. In the current the logistics industry of our country lack of the professionals engaged in research, management, planning and design, basic operation. By now, most employees didn't acquire professional acknowledge, most of them is from computer and management industry[3]. And now most of logistics management talents cannot really meet the actual demand of logistics enterprises. More specifically, the overall quality of the logistics practitioners is relatively low, the high-quality personnel who master both knowledge management and technology are less. Logistics education, training and certification work lag behind, due to the foundation of the logistics professional education in China starts late, and colleges and universities have the logistics department are less, and high-qualified and professional teachers of the logistics department are lack seriously, and most of the graduates are not engaged in the logistics industry. These factors bring the negative effect to the rapid development of green logistics.

(7) There is no effective way to add up, analysis and evaluate the results of implementation, even to adjust the planning and policy. Developed countries pay attention to policy adjustment and improvement, to make explicit review system in the implementation of the policy, make the public know the implementation, carry out the rolling review, and adjust the planning and policy in time according to the problems appeared in the process of the implementation of the policy. However, the implementation effect of China's green logistics policy is lack of tracking and dynamic adjustment, and lack of reasonable performance appraisal and inspection mechanism, so that the effect of policy implementation can not be evaluated and improved. In addition, the results of the implementation of China's policies are not opened, is un-benefit to supervise for the social and public opinion, as well as to promote the implementation and improvement of the policy.

\section{Summary}

The modern green logistics management is a kind of new logistics management mode, which is based on the protection of the ecological environment. From the perspective of long-term development, green logistics management need to meet customer demand, and overcome the 
logistics services in the temporal and spatial barriers at the same time. It is not only helps to create a green image for the enterprises, but also in accordance with the requirements of the development and people's fundamental interests, becoming the direction and trend in the development of modern logistics management.

\section{References}

[1] Wang Changqiong, Green Losgitics, Chemical Industry Press, Beijing, 2004

[2] ZHAO Dan, Discuss on Green Losgitics of China,Time Finance,577(2015)222-223

[3] Guo Wei, Research on Management and strategy of modern Green Losgitics, Modern Marketing,17(2013)52-53 